\title{
Recuperar la esperanza
}

\author{
Teresa PEREIRA RODRÍGUEZ ${ }^{1}$ \\ tpereira@telefonica.net
}

Recibido: $05 / 06 / 12$

Aceptado: 22/11/12

\section{RESUMEN}

Caso clínico de una participante en un Taller de Arteterapia para mujeres maltratadas. Expondremos como desde un primer estado de confusión, escepticismo y bloqueo, y a través del trabajo creativo de las sesiones que facilitó un ejercicio de expresión, análisis y reflexión, esta mujer pudo hacer una relectura y desbloqueo de su biografía, sentimientos y emociones, empezando a entrever al final una esperanza de presente y de futuro.

Palabras clave: Arteterapia, maltrato, violencia de género, bloqueo, miedo, soledad, esperanza.

\section{Referencia normalizada}

Pereira Rodríguez, T. (2012). "Recuperar la esperanza". En Arteterapia: Papeles de arteterapia y educación artística para la inclusión social Vol.7: páginas 59-78. Madrid. Servicio de publicaciones UCM.

\section{SUMARIO}

Introducción. Arteterapia y maltrato. Caso clínico: consideraciones iniciales. Recuperar la esperanza. Conclusión.

\section{ABSTRACT}

\section{Recovering hope}

A clinical case about a participant in an Art Therapy Workshop for battered women. We will present how, from an initial state of confusion, skepticism, and blockage and through the sessions' creative work which led exercises of expression, analysis and reflection, this woman was able to reread and unblock her own biography, feelings and emotions, beginning to catch a glitter of hope for her present and future.

Keywords: Art therapy, abuse, gender abuse, blockage, fear, loneliness, hope.

\section{CONTENTS}

Introduction. Art Therapy and abuse. A clinical case: preliminary considerations. Recovering hope. Conclussion.

${ }^{1}$ Licenciada en Bellas Artes, máster en Arteterapia y DEA por la Universidad Complutense de Madrid. Ha colaborado como docente el máster en Arteterapia de la Universidad Complutense de Madrid y en los Cursos de Verano de la misma universidad y de la Universidad Pablo Olavide de Sevilla. 


\section{INTRODUCCIÓN}

El Instituto de Investigaciones Feministas de la Universidad Complutense de Madrid organizó, el 26 de abril de 2012, un Seminario de Terapias Feministas en el que se nos invitó a varias arteterapeutas a impartir diversas ponencias sobre casos clínicos de mujeres que hubiésemos atendido en nuestra vida profesional. La revista Arteterapia: Papeles de arteterapia y educación artística para la inclusión social nos propuso su publicación en el Vol. 07 de la misma. Este texto responde a esa iniciativa con respecto a mi ponencia Recuperar la esperanza, en la que exponía el caso clínico de una de las participantes en un taller de Arteterapia para mujeres maltratadas, aunque la presentación original ha sido ampliada con el capítulo siguiente para centrar de forma resumida el tema del que se ocupa, Arteterapia y maltrato.

La elección de este caso obedeció a que aunque mi trabajo como arteterapeuta se ha desarrollado atendiendo a varios colectivos, ha sido el de las mujeres maltratadas en el que he tenido ocasión de invertir más tiempo y acumular diversidad de experiencias. Esta circunstancia me llevó a plantearme la investigación doctoral, hoy en proceso de elaboración y titulada Arteterapia y mujeres maltratadas: Acompañando a las mujeres rotas, sobre la aplicación del Arteterapia en este colectivo. En ella, además de defender la efectividad del Arteterapia en este campo, pretendo presentar el diseño de un modelo o estrategia de intervención arteterapéutica apropiado para las necesidades específicas de su problemática. La investigación está enfocada desde un punto de vista más cualitativo que cuantitativo, más que acumular datos se aportan datos y más que investigar a las mujeres maltratadas se investiga con ellas, partiendo de aceptar que el conocimiento puede ser en parte subjetivo, la participación activa del investigador y su implicación emocional.

En mi investigación han sido muy enriquecedores los trabajos y publicaciones de otras compañeras sobre el mismo tema en España, como Marian Alonso (2012), Pilar Ascaso, Marina Ojeda (2008), Montse Omenat (2006) o Ana Serrano (2008); no desdeñando ni desconociendo los trabajos realizados en otros países, pero considerando más interesante los logros y las aportaciones que se puedan hacer desde un entorno con una idiosincrasia común, que incluye el hecho de que a los talleres de todas han acudido mujeres procedentes de las muy diversas culturas establecidas por diferentes motivos en nuestro país. Sin olvidar las publicaciones, la docencia y el apoyo que han supuesto y suponen las que fueron directoras del Master de Arteterapia de la UCM cuando yo lo cursé, Noemí Martínez (hoy directora de mi tesis) y Marián López F. Cao (2009). 


\section{ARTETERAPIA Y MALTRATO ${ }^{2}$}

En España, según los datos facilitados por el Instituto de la Mujer, durante el año 2011 murieron 61 mujeres a manos de su pareja o ex-pareja y en el primer semestre 2012 han muerto ya 26. Estos datos abrumadores constatan que a pesar de los esfuerzos que, tanto la Administración como distintas asociaciones de ciudadanos, especialmente de mujeres, vienen haciendo estos últimos años, nuestra sociedad no ha podido o no ha sabido todavía dar solución a este problema. El objetivo de este capítulo es acercarnos a esta dura realidad desde la experiencia de la utilización del Arteterapia como herramienta eficaz para atender al colectivo de las mujeres maltratadas.

La elección de la expresión "mujeres maltratadas" se ha hecho atendiendo a la definición que uno de los estudiosos del tema, Miguel Lorente Acosta, sobre lo que él denomina Síndrome de Agresión a la Mujer:

Aquel que hace referencia a todas aquellas agresiones que sufre la mujer como consecuencia de los condicionamientos socioculturales que actúan sobre el género masculino y femenino, situando a la mujer en una posición de inferioridad y subordinación al hombre, y manifestadas en los tres ámbitos básicos en los que se relaciona una persona: en el seno de una relación de pareja, en forma de maltrato; en la vida en sociedad como agresiones sexuales; y en el medio laboral como acoso sexual. (Lorente, 2001-39)

Delimitado nuestro ámbito de estudio en el supuesto de las mujeres agredidas en el seno de una relación de pareja, sea cual sea su estado civil o de convivencia, nos planteamos, desde un punto de vista teórico, las preguntas básicas que suscita el tema; para centrarnos después en la intervención arteterapéutica.

La primera pregunta a la que debemos responder es el por qué de la existencia de esta lacra. Esto nos conduce inevitablemente a analizar la propia naturaleza de la violencia, extremo que es demasiado extenso y complicado para las pretensiones de este texto, y las distintas formas que ésta adopta en el caso que nos ocupa. Baste decir que la violencia constituye una de las tres principales fuentes del poder humano; las otras dos son el conocimiento y el dinero. Como afirma Miguel Lorente (2001), la violencia funciona, a los agresores les va bien actuando de este modo; por lo general consiguen lo quieren, obtienen más resultados deseados que fracasos. En el caso del maltrato es evidente que los condicionamientos socioculturales, en especial la sociedad patriarcal, son su origen principal. A pesar de todas las medidas y esfuerzos que se han invertido para afrontarlo lo que aflora de él no es más que la "punta del iceberg" de una realidad social, que abarca un amplio espectro de tipos de violencia, crueldad y vejación, que en la mayor parte de los casos, como postula Patrizia Romito (2007), se encuentra sumergida en el silencio, la vergüenza y la soledad. Este maltrato puede ser de varios tipos, físico, sexual o psicológico, inclu-

\footnotetext{
${ }^{2}$ El contenido de este capítulo se basa fundamentalmente y de forma resumida en mi artículo “Acompañando a las mujeres rotas" (2009) que ha sido el germen sobre el que he comenzado a escribir mi tesis doctoral.
} 
yendo este último los malos tratos sociales, ambientales o económicos, y pueden producirse todos ellos a la vez o no. Si bien, el maltrato psicológico está invariablemente asociado al maltrato físico o sexual y, en el maltrato psicológico, incluso en las mujeres que afirman que nunca estuvieron sometidas al físico o al sexual, es frecuente descubrir, al profundizar en él, formas mucho más sutiles y perversas de maltrato físico o sexual.

El cómo se produce y se mantiene una relación de maltrato sería la segunda cuestión básica a plantearse. A menudo no se comprende como estas mujeres pueden permanecer durante tantos años sufriendo esta situación. Esta cuestión fue abordada ya en el siglo pasado por la investigadora Leonore Walker (1979), describiendo el Ciclo de la violencia doméstica de una forma clara y realista, postulando que éste pasa por tres fases: fase de tensión (escalada gradual de las fricciones y los conflictos), fase de agresión (estalla la violencia y aparece el maltrato) y fase de conciliación (la tensión y la violencia desaparecen, el agresor pide perdón y la mujer decide mantener la relación). A medida que pasa el tiempo aumenta la duración de las dos primeras fases y disminuye la última, hasta llegar a desaparecer. La mujer atrapada en esta relación de amor y pánico, vive sumida en el miedo, la soledad, la culpa y el dolor, estableciéndose una fuerte dependencia y sumisión del maltratador, que le aboca, si no es capaz de romper el ciclo, a perder su autoestima, su independencia y el poder sobre las decisiones de su vida. Si bien este ciclo no siempre se produce de una forma rigurosa y esta teoría ha sido a veces malinterpretada por algunas instancias al no reconocer en ciertos casos el maltrato si no se ajustaba a estas pautas, es indudable que permitió empezar a comprender y a centrar la situación de la mujer maltratada; la de una mujer sometida a un proceso claramente generado por el miedo, agravado por la implicación emocional de la víctima con su agresor y potenciado por el aislamiento y la carencia de apoyo externo perceptible.

Su comprensión nos lleva a preguntarnos sobre quiénes pueden llegar a encontrarse en esta situación, es decir, si existe un perfil de mujer maltratada o de maltratador. Son muchas las opiniones y teorías al respecto y, además, éstas han ido variando desde los primeros intentos de acercamiento al problema hasta hoy en día. Lo cierto es que el maltrato se da en cualquier condición histórica, social o económica y se agrava en situaciones límite de cualquiera de ellas, siendo la educación, los valores y los estereotipos aprendidos las bases que lo sustentan. No parece haber una psicopatología subyacente en la victima, aunque algunas situaciones como el abuso infantil o el maltrato en la familia de origen, una crisis vital temporal o una pérdida puedan hacerla vulnerable a reproducir o caer en el maltrato. Lo que sí parece claro es que, en el caso de la mujer, las consecuencias de éste se traducirán en graves alteraciones psíquicas, físicas o emocionales que si no son atendidas convenientemente frustrarán permanentemente su vida; cuando no se de el caso más trágico de que simplemente la pierda.

Todo esto nos lleva a plantearnos qué tipo de intervención, según los especialistas, puede ayudarles no solo a salir de su situación, sino a ser capaces de afrontar una nueva vida. Aunque el caso de cada mujer ha de ser considerado de un modo individual y su biografía y estado anímico determinarán cual es la intervención más 
adecuada, podemos decir que la indefensión y pasividad, el permanecer atrapada en su pasado, la depresión, la somatización, la ira y el abandono de sus relaciones, lealtades y valores humanos caracterizan el estado en que se encuentra la mujer después de una relación de maltrato. A lo largo del tiempo su situación ha sido descrita por los especialistas con muchos nombres y desde la psiquiatría se ha incluido en muy diversas categorías. Hoy en día parece claro que la mujer que ha estado sometida a una relación de maltrato, sobre todo cuando ésta ha sido prolongada y repetida, desarrolla lo que Judith Herman (2004) diagnosticó como "Desorden de estrés postraumático complejo". Su definición especificaba todas las alteraciones que se pueden observar en el comportamiento de determinadas víctimas, entre ellas las mujeres maltratadas: en la regulación de las impresiones, en la conciencia, en la percepción de uno mismo, en la percepción del perpetrador, en las relaciones con los demás y en los sistemas de significado. Además desarrolla una propuesta de recuperación que se basa fundamentalmente el devolver el poder a la víctima y en la creación de nuevas conexiones para poder recrear las facultades psicológicas dañadas: confianza, autoestima, iniciativa, competencia, identidad e intimidad. Planteó por último una estrategia en el desarrollo de la recuperación estructurándola en tres fases. En la primera lo principal es establecer la seguridad; en la segunda la tarea será el recuerdo y el luto; y en la tercera se potenciará la reconexión con la vida normal. Como afirma Judith Herman (2004), la sincronización de la integridad y la confianza en las relaciones hará que la paciente recupere el sentido de una comunidad humana que el trauma había destruido.

En la reconstrucción de esa integridad, hay otro concepto, que aunque antiguo es nuevo aplicado a las teorías sobre el comportamiento humano, que va a jugar un papel muy importante y por el que profesionales de ámbitos diversos, psicólogos, psiquiatras, educadores o filósofos, se han interesado especialmente en estos últimos años, este es el concepto de la resiliencia. Ésta se define como capacidad que tiene un ser humano (niño, adolescente, adulto) a pesar de sus dificultades personales (físicas, mentales y psíquicas), para intuir y crear, en circunstancia desfavorables o en un entorno destructor, respuestas que le hicieran posible no dejarse atrapar por las circunstancias y tropiezos personales ni por las condiciones del entorno, sino por el contrario proponer y realizar comportamientos que le permitieran una vida con menos sufrimiento y encontrar un lugar en su medio ambiente, lo cual le permitirá desarrollar sus capacidades y anhelos; la resiliencia no sólo supone una resistencia frente a la destrucción, sino una capacidad para construir o reconstruir su propia vida.

Cabe pensar entonces, que activar este potencial tanto en los procesos de crecimiento como en cualquier situación de crisis, conflicto o dificultades físicas, psíquicas o cognitivas, va a permitir no solo afrontarla sino hacer de ella una experiencia enriquecedora. Pero, ¿cómo activar este potencial? Todos los estudiosos de este concepto están de acuerdo en afirmar que son la vincularidad, el sentido del humor y la creatividad los factores fundamentales que influyen en la formación de comportamientos y actitudes resilientes.

Partiendo de todos los supuestos anteriores, estamos en condiciones de abordar cual es el papel que puede jugar aquí el Arteterapia y por qué es una disciplina es- 
pecialmente indicada en el caso del maltrato. El Arteterapia se define como una disciplina especializada en acompañar, facilitar y posibilitar un cambio significativo en la persona mediante la utilización de diversos medios artísticos: atendiendo a su proceso creativo, a las imágenes que produce y a las preguntas y respuestas que éstas le suscitan. Ya que el Arteterapia se basa en el convencimiento del poder del arte y utiliza la creación artística como un canal alternativo de expresión y como una fuerza generadora positiva, podemos deducir que será una herramienta o estrategia perfecta para crear o activar ese potencial resiliente convocado por diversas circunstancias y, en concreto, por la que nos ocupa en este texto, reconstruir la vida de mujeres desestructuradas y heridas por haber sido agredidas en el seno de una relación de pareja.

Aunque la intervención arteterapéutica se puede acometer tanto forma individual, como de grupo, en el caso concreto de las mujeres maltratadas y por toda la casuística descrita anteriormente se considera que el grupo es especialmente beneficioso para ellas, al margen de que puedan recibir también de forma individual apoyo de otros especialistas y profesionales. Es más, es el trabajo en equipo de todos lo que de forma correcta y efectiva puede ayudarlas en su recuperación.

El primer objetivo de nuestra intervención será crear un espacio propio, lúdico, creativo, reflexivo y expresivo. Desde él nuestro principal objetivo será devolver la autonomía personal a las participantes, fortaleciendo su autoestima, facilitando el autoconocimiento y la construcción de un discurso positivo cara el futuro. Para ello tendremos que destapar y trabajar los mecanismos de defesa y supervivencia cronificados, reconociendo las distorsiones o la falta de conciencia de la realidad y desbloqueando sentimientos y emociones largamente reprimidos u olvidados.

Además, el trabajo arteterapeútico tendrá una especial importancia ya que los recuerdos traumáticos carecen de una narrativa verbal y de un contexto, y están codificados en forma de sensaciones vividas e imágenes. Desde ahí, la expresión plástica de éstos va a resultar un puente y un recurso perfecto entre la mujer y su pasado, y va a suponer también una forma más de testimonio de su historia. En su análisis del trauma Judith Herman apuntaba:

(...) A la paciente le resultará cada vez más difícil utilizar las palabras a medida que la narrativa se acerca a los momentos más insoportables de su historia traumática, y, en ocasiones, la paciente puede recurrir espontáneamente a otros métodos de comunicación no verbales como los dibujos. Dada la naturaleza visual "icónica" de los recuerdos traumáticos, crear dibujos puede representar la primera aproximación más efectiva a estas "imágenes imborrables". La narrativa completa debe incluir una descripción vivida y completa de la imaginaría traumática. (Herman, 2004:274)

Por otro lado el taller se convertirá en un lugar de encuentro que les facilitará romper su aislamiento, compartir experiencias, solidarizarse y sentirse útiles, recuperando esa vincularidad indispensable para su recuperación.

La estrategia de intervención en cada taller de Arteterapia vendrá determinada por muchos factores: el número participantes, el estado físico, emocional y psíquico de cada una de ellas, el entorno económico, social y cultural de las mismas, la temporalización y duración de los talleres, etc.; pero en términos generales después de lo 
expuesto en este capítulo sobre Arteterapia y maltrato, de la experiencia acumulada y de los resultados que poco a poco va dando la investigación se ha ido dibujando un modelo de taller estructurado en tres etapas:

Una primera etapa en que se plantean trabajos plásticos sencillos que les permitan tanto familiarizarse con los materiales y las técnicas, como ir descubriendo cuales serán sus preferencias y con cuales se expresan con más libertad. También permitirán valorar cuál es el nivel plástico y creativo de las participantes y revisar los primeros datos sobre sus relaciones más importantes, el estado de su relación con el maltratador y su situación vital en los aspectos laborales, económicos y judiciales, comenzando a animarles a expresar también sus estados de ánimo.

En la segunda se hace un largo recorrido por sus biografías, desde su infancia hasta su situación actual, revisando acontecimientos, relaciones importantes, ideales y sueños, luchas y conflictos. Se tratará entonces de proponer actividades que les ayuden a evocar sus recuerdos y sentimientos para expresarlos de una forma espontánea y proyectiva plásticamente. Todo este proceso será especialmente doloroso para las mujeres, pero les ayudara a comprender el significado de los hechos tanto para ellas, como para las personas más cercanas. Reconstruir todo el ciclo de la violencia doméstica en sus propios casos y sentirlo reflejado, además, en el de sus compañeras, les permitirá no solo entender el transcurrir de los hechos y el por qué de sus respuestas, sino también como un "antes y un después" habían condicionado muchas de ellas.

$\mathrm{Y}$ una tercera etapa centrándose más en el presente y el futuro de sus vidas. Las propuestas se orientarán en redibujar la imagen de sí mismas, examinando el estado de su autoestima y fortaleciendo su nuevo yo. Esta revisión abarca desde el estado de su propio cuerpo hasta sus pautas organizativas o la forma en que se relacionan en sus entornos laborales y familiares en el presente, destapando comportamientos dependientes y actitudes recurrentes o viciadas.

Estas etapas no deben ser por supuesto cerradas, solo son una guía sobre la que sustentar el taller que siempre se desarrollará siguiendo las pautas que vayan exigiendo las necesidades del mismo. En la misma línea una sesión cualquiera se planifica en términos generales con una propuesta de trabajo y una puesta en común del mismo, pero siempre será el proceso lo más importante y lo que determinará la evolución de la misma. Desde aquí, hay que intentar ser concretos, centrando la experiencia, para lo cual se debe disponer de una amplitud de recursos, tanto desde el punto de vista de las actividades a proponer, como de las técnicas y materiales utilizados, que nos permitan que el desarrollo tanto de las sesiones como del taller sea una experiencia viva que vaya creciendo y buscando su propio camino.

Desde los postulados del Arteterapia se trata de abordar las sesiones con una actitud de respeto y acompañamiento, intentado establecer con las participantes una corriente de empatía y aceptación que facilitará la comunicación y la intervención desde un posicionamiento constructivista e humanista. Miedo, soledad, dolor y culpa serán los principales sentimientos y emociones que irán aflorando a lo largo del taller, pero para una mayoría de las mujeres el afrontamiento de ellos, desde el des- 
velamiento, la revisión y análisis que les facilita el Arteterapia, hará que al final vislumbren por fin la esperanza en sus vidas.

\section{CASO CLÍNICO: CONSIDERACIONES INICIALES}

Cuando Elena (nombre ficticio) aceptó voluntariamente participar en el Taller de Arteterapia, ofertado por la "Comisión para la investigación de malos tratos a mujeres", llevaba ya un año en el programa de ayuda y apoyo del Centro de Atención a Mujeres Maltratadas de dicha asociación. Allí había recibido tanto orientación laboral como asesoría jurídica y se le había incluido en el servicio de Apoyo Psicológico, donde se le facilitaron terapia individual, charlas informativas y otras actividades como la "Escuela de Padres". Este servicio, después del seguimiento previo, la derivó a nuestro Taller de Arteterapia, en el que se trabajó conjuntamente con la psicóloga del centro, Dolores Ortega.

El que Elena llevase ya un periodo siendo atendida por la asociación es el primer aspecto importante de este caso. Cuando una mujer recurre a los servicios de auxilio se valora si su situación aconseja el ingreso en una casa de acogida, dada su extrema peligrosidad, o si las mínimas exigencias de seguridad están satisfechas y se le remite a un centro externo de atención. La situación psíquica, física y emocional es muy diferente en un caso u otro, aunque pueda ser igual de compleja o grave. Después de la decisión más importante, la de abandonar al maltratador, Elena había sido capaz de pedir ayuda y entonces los servicios de auxilio valoraron su caso y le aconsejaron acudir a un centro externo, después de comprobar que existía una garantía de entorno seguro y unas necesidades mínimas cubiertas. A partir de ahí, comenzó a recibir la ayuda de los diferentes profesionales del mismo y, por tanto, cuando llegó a nuestro taller ya había comenzado a dar los primeros pasos para su recuperación.

Otro aspecto importante del caso es el que demuestra una premisa de la que siempre hemos partido al trabajar con mujeres sometidas a violencia de género y que en muchas ocasiones se pone en duda: el maltrato puede darse en cualquier condición histórica, social o económica aunque se intensifique en situaciones límite de cualquiera de ellas. En nuestro caso, la pareja, que llevaba 22 años de matrimonio, pertenecía a una clase social acomodada, él era médico psiquiatra y ella psicóloga. Elena trabajó en atención al cliente de distintas empresas hasta que tuvo su primer hijo y pasó a ser ama de casa exclusivamente. Tenían un nivel adquisitivo alto, vivían en un chalet de una urbanización, se movían en un ambiente culto y podían consentirse viajes o vacaciones con desahogo. Ante una situación de maltrato algunas mujeres disponen de los recursos psicológicos y los apoyos afectivos y sociales suficientes para poder defenderse a tiempo o sobreponerse a ello; cuando no es así, necesitaran la ayuda y el apoyo de especialistas para salir del inevitable trauma que genera la exposición, sobre todo si es prolongada, a la violencia ejercida por el hombre en el seno de una relación de pareja. En el caso de Elena, su situación social y económica no la libró de vivir una relación de maltrato, ni tampoco su alta capacidad intelectual y formación superior impidieron que tardara años en distin- 
guirla y ser capaz de afrontarla y, evidentemente, su entorno tampoco pudo o supo protegerla o ayudarla.

Elena se había separado del maltratador dos años antes y se encontraba en trámites de un complicado divorcio. Él había puesto casi todos los bienes a nombre de otros familiares y ocultaba la mayor parte de sus ingresos, por lo que la sentencia apenas le reconocía una pequeña pensión, a pesar de tener a su cargo los dos hijos del matrimonio, un adolescente de 17 años y una niña de 11, haciéndose cargo el padre tan sólo de la escolarización de los hijos. Ella la había recurrido ante la Audiencia Nacional y, aunque sus asesores creían que estimarían favorablemente el recurso, él había amenazado con estar dispuesto a recurrir a su vez y llegar hasta la última instancia judicial prolongando el proceso, y por tanto su situación de inestabilidad, el máximo tiempo posible. Sin apenas experiencia laboral sólo había conseguido trabajos eventuales de teleoperadora o encuestadora, siendo su situación económica bastante precaria. Mientras, seguía viviendo con sus hijos, que también habían recibido ayuda psicológica del centro, en el domicilio conyugal, que le había sido adjudicado en las diligencias previas. Por su parte, él vivía en una localidad cercana, viendo a sus hijos los días estipulados.

Aunque Elena aseguró desde el principio que durante su convivencia sólo había estado sometida a maltrato psicológico, reconociendo la fuerte dominación que su pareja ejercía sobre ella, cuando decidió separarse él reaccionó de forma agresiva y acosadora y entonces empezó a tenerle auténtico miedo. Cuando recibió llamadas constantes de teléfono, comprobó que la seguía y que vigilaba su casa, pidió y consiguió una orden de alejamiento.

Estas son las consideraciones iniciales que en términos generales y objetivos nos permiten describir la situación vital de Elena cuando acudió al taller. A lo largo del mismo se irían desgranando su estado anímico, emocional y afectivo.

\section{RECUPERAR LA ESPERANZA}

ESPERANZA: Estado de ánimo en el cual se nos presenta como posible lo que deseamos.

RAE

En el taller participaron 4 mujeres, el máximo que permitía el lugar de trabajo facilitado por la asociación: una sala, suficientemente iluminada, con una mesa de reuniones, agua en un baño próximo y espacio en una estantería para guardar los materiales; si bien las condiciones no eran las ideales resultaban aceptables, sobre todo porque su ubicación garantizaba independencia e intimidad con respecto al resto de actividades del centro. Se realizaron 43 sesiones de dos horas semanales durante un año, de junio a junio, con interrupciones coincidentes con las vacaciones de verano, Navidad y Semana Santa (aunque esta última no se considera como tal ya que solo fue de una sesión).

Elena tenía entonces 49 años, era una mujer guapa de aspecto robusto (ganó peso después de la separación), vestía de forma austera sin ninguna concesión a la 
coquetería y emanaba mucha tristeza. Siempre se daba un tiempo antes de empezar el trabajo propuesto y lo hacía lentamente como si fuera encontrando poco a poco lo que quería. Plásticamente tenía un nivel de recursos alto, siempre le había gustado dibujar pero hacía mucho tiempo que no lo hacía, fue uno de los motivos por los que se animó a apuntarse al taller. A lo largo del mismo se le animó a que recuperara esa afición para sí misma, no sólo en las sesiones, sino también en su vida habitual. Verbalmente se expresaba muy bien, con un lenguaje medido y culto con el que lograba transmitir con bastante precisión sus ideas y sentimientos.

En las primeras sesiones, además de aportar los primeros datos básicos de su situación personal, expresó claramente la sensación de vacío y desubicación en la que se encontraba, pensaba que estaba en un túnel y todavía no veía la luz, pero estaba dispuesta a luchar.

Cuando se le pidió hacer un collage con recortes de revistas, El cartel de una misma, exponiendo en él como se presentaría ella ante los demás, se representó como un monigote, una patata, algo informe, sin estructura, perdida entre interrogaciones y trabajos agobiantes. Esto ocurría hasta que, en un punto de su composición, decía Alto y comenzaba a pegar imágenes de sus deseos (conocer nueva gente, recuperar sus aficiones,...) y un recorte con el texto asignaturas pendientes; vivir en positivo al fin (Imagen 1-1).

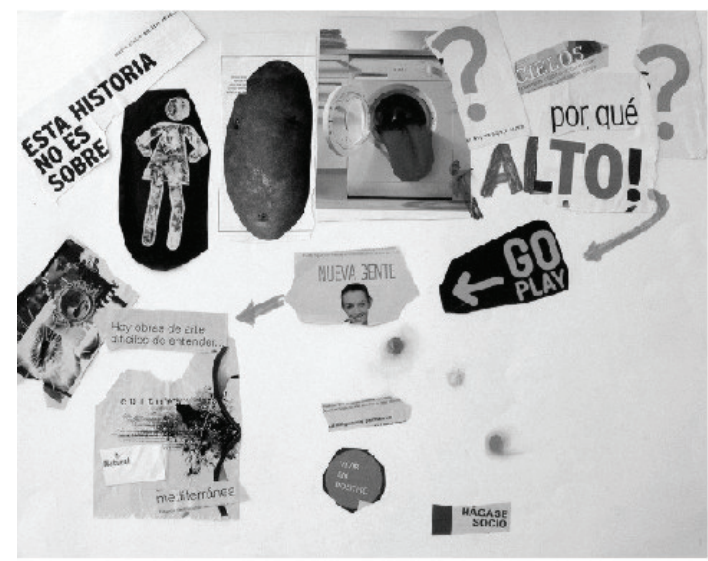

Imagen 1-1

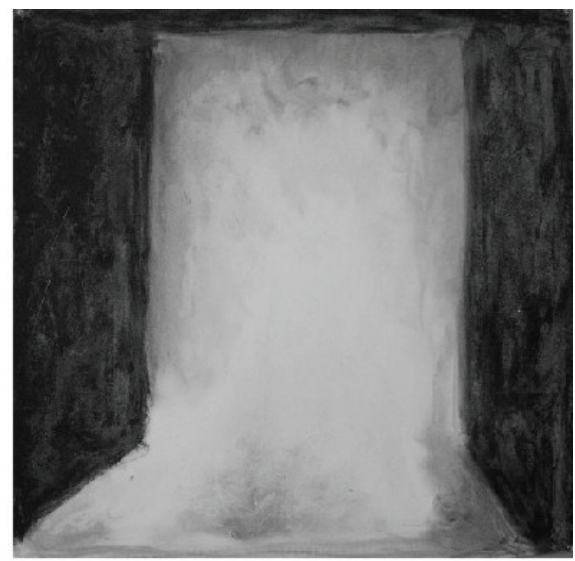

Imagen 1-2

En la misma línea realizó una ilustración (Imagen 1-2) sobre lo que le evocaba la lectura del cuento Los tres cabellos de oro de Clarissa Pinkola (2001). El cuento relataba como un anciano cansado avanzaba por el bosque, en la oscuridad, apenas iluminado por una lámpara, hasta una casa donde una anciana lo acogía, lo acunaba y lo cuida, y donde un gran fuego daba calor a la estancia. Poco a poco el viejo iba rejuveneciendo llegando a convertirse en un bebé dorado. Por fin, la vieja le arrancaba tres cabellos de oro y el niño se convertía en luz, uniéndose al sol. El relato era una metáfora de la necesidad de pedir ayuda, de dejarse cuidar, de abandonar ciertas cosas aunque parezcan valiosas, para poder recuperar la energía. Elena dijo que 
para ella el cuento significaba el tránsito a la luz, ella había reconocido la necesidad de ser cuidada y atendida, sabía que ese calor era necesario para poder salir por el umbral que había representado en su dibujo.

Cuando se le pidió a Elena en otra de las sesiones que realizara una composición sobre su estado de ánimo a través de alguna imagen que le viniese a la cabeza sin reflexionar demasiado, o de algún sueño que hubiese tenido, su trabajo (Imagen 21) reflejó el estado de abandono típico de la constricción. Como explica Judith Herman (2004) el peligro no solo había provocado terror o ira, sino una paradójica y extraña calma en la que se disolvía la angustia. Los acontecimientos y las experiencias perdían su calidad de realidad normal, todo parecía moverse a cámara lenta. La indiferencia, el extrañamiento emocional y la pasividad anulaban toda iniciativa o resistencia. Aún habiendo desaparecido el peligro este escudo protector se mantenía como una manta pesada de la el sujeto no se sentía capaz de deshacerse.

Elena había soñado que viajaba, no sabía adonde, estaba sola, todo estaba silencioso y la ciudad estaba envuelta en brumas, intentaba alargar la mano pero no conseguía tocar nada, ni ver a nadie, sentía un frío intenso, como si estuviera congelada, no podía moverse. Asi me siento yo, flotando, envuelta en algo frío que me rodea, paralizada.

Contemplando su dibujo solo veía desolación, perplejidad por la soledad. Relató entonces que empezó a tener consciencia de su relación de maltrato cuando se enteró de que él había sido acusado por una compañera de trabajo de acoso sexual. Aunque lo negaba todo, los hechos y los conocidos ratificaron el delito y Elena descubrió una doble vida de infidelidades y engaños, comprendiendo entonces muchas ausencias, excusas y actitudes de él. Su vida se vino abajo y una gran desconfianza y desapego se extendieron también hacia sí misma y hacia su entorno.

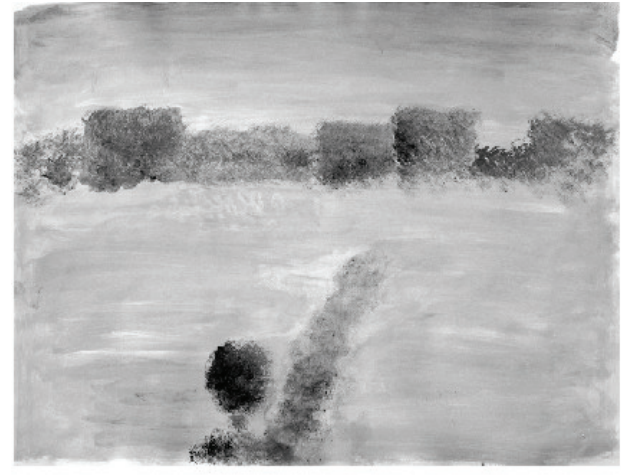

Imagen 2-1

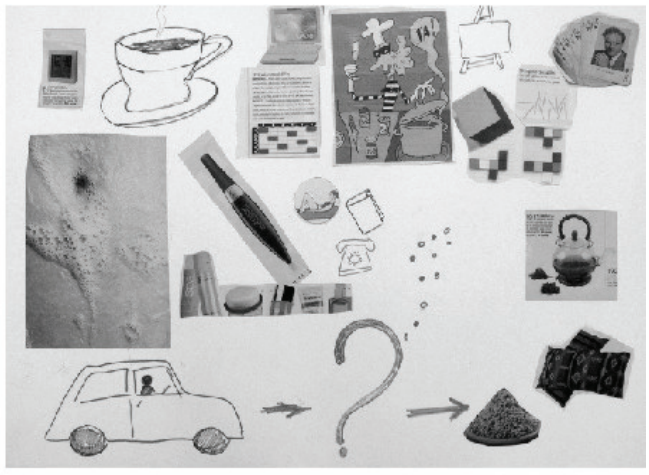

Imagen 2-2

En las sesiones siguientes insistió en esa sensación de desorientación y cansancio. Se le propuso entonces que hiciese un trabajo sobre el Cuadro de un día en el que meditara sobre todas las actividades que realizaba en un día corriente. En su composición (Imagen 2-2) reflejó varias cosas positivas, como por ejemplo, que volvía a disfrutar de aficiones (la cocina, la pintura, jugar con su hija,...) o a dedi- 
carse un tiempo a si misma, ya fuera en la lectura, el cuidado personal o a gozar de momentos pequeños como tomarse un café o un té. Sin embargo le angustiaba mucho la cuestión laboral, que representó con un gran interrogante de la parte inferior de su composición, todos los días tenía que salir con su coche a buscar trabajo para poder afrontar la manutención de sus hijos y de sí misma. Se arrepentía de no haber seguido con su carrera, le gustaría poder encontrar algo relacionado con la psicología, creía que en su momento tomó la decisión equivocada y ahora no le quedaba más remedio que asumirlo. Reconocía que él le animó a que se quedara en casa y que ella entonces pensó que era lo mejor para todos.

Antes de la primera interrupción del taller, que se produjo en el mes de agosto por las vacaciones de verano, se hizo una revisión de todos los trabajos hechos hasta esa fecha. Elena reconoció su sorpresa por todo lo que había conseguido expresar a través de su obra y de cuanto le ayudaba a reflexionar sobre su situación, sobre todo a empezar a entender donde estaba. En septiembre, cuando se reanudaron las sesiones, contó que agosto había sido un mes claro-oscuro, que por un lado había elaborado muchas cosas, pero que también se había sentido muy sola. Además había comenzado a cambiar algunas cosas en su casa, deshaciendo la habitación de matrimonio, convirtiéndola en su estudio, y pasando su dormitorio a una habitación nueva. Comentó que esto le había hecho sentir muy bien, que le parecía que empezaba una etapa nueva de su vida.

En esta nueva fase del taller, considerando que el grupo y el vínculo con las participantes estaban asentados y consolidados, propusimos a las mujeres que en las sesiones siguientes hiciésemos un recorrido por sus biografías, analizando situaciones, personajes y sentimientos, hasta donde cada una de ellas quisiera voluntariamente profundizar.

Poco a poco Elena, a través de distintas propuestas de trabajo que le ayudaran a evocar sus recuerdos, fue relatando su biografía. Su familia no era de Madrid, nació y se crió en otra capital de provincia y allí vivió con sus padres y sus dos hermanos, ella era la mayor. La familia de su madre era gente adinerada, su padre, un trabajador corriente, había sido considerado por ellos poco valioso para su hija, extremo que siempre le molestó profundamente. Su trabajo le mantenía frecuentemente fuera de casa, por lo que una de las primeras imágenes de su familia que representa, en una propuesta sobre reconstruir con plastilina la casa de su infancia (Imagen 3-1), es a todos ellos comiendo juntos alrededor de la mesa, eran momentos felices en los que estaba toda la familia reunida (Imagen 3-2). La figura de su padre había sido muy importante para ella, él siempre intercedía a su favor en las numerosas discusiones que mantenía con su madre, con quien la relación era más conflictiva. En el momento del taller su padre ya había muerto años atrás y su madre y sus hermanos seguían viviendo en su ciudad natal y se veían poco. 


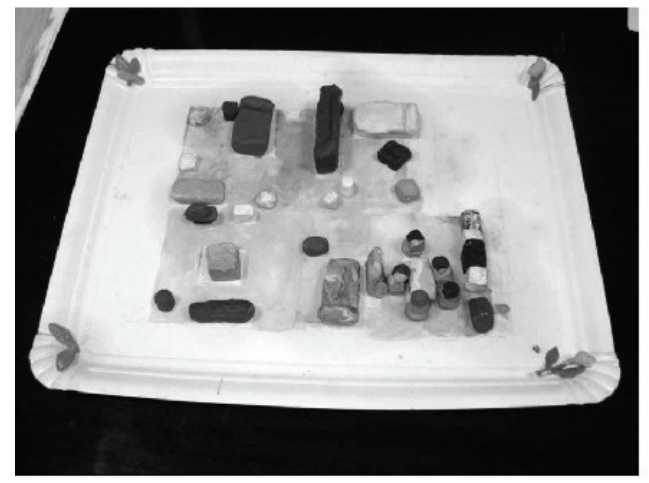

Imagen 3-1

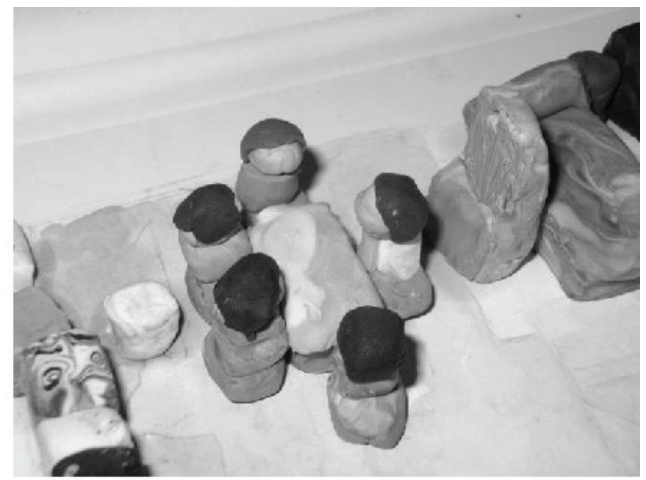

Imagen 3-2

episodio que dijo haber olvidado y rememorado en esos días. Como se demoraba mucho se le animó a terminarlo en casa y traerlo a la semana siguiente. En la siguiente sesión trajo entonces varios dibujos y relató que su educación había sido muy rígida, en especial su madre era extremadamente severa. Cuando ella se rebeló, ante lo que consideraba una aplicación caprichosa de reglas mezquinas por parte de su progenitora, fue internada en un colegio de monjas por un largo periodo, sin que su padre intercediera esta vez por ella. Era un recuerdo que tenía olvidado, se sorprendió de haber sido capaz de dibujarlo y de los sentimientos que había experimentado al hacerlo (Imagen 4-1). Rememoró el frío y la suciedad del lugar, la arbitrariedad de las normas del colegio, y, sobre todo, la sensación de abandono y exclusión familiar. Nunca llegó a comprender el porqué de aquella decisión de sus padres que consideraba totalmente injusta, $\mathrm{y}$, aunque volvió después al entorno familiar, no fue capaz de reestablecer una relación saludable con ellos. Se podría pensar entonces que Elena había estado sometida a un mal trato emocional, que probablemente tenía mucho que ver con la dificultad que ella misma reconocía posteriormente para sentirse parte de algo y que, posiblemente, le abocó al deslumbramiento y la sumisión que estableció en su relación de pareja.

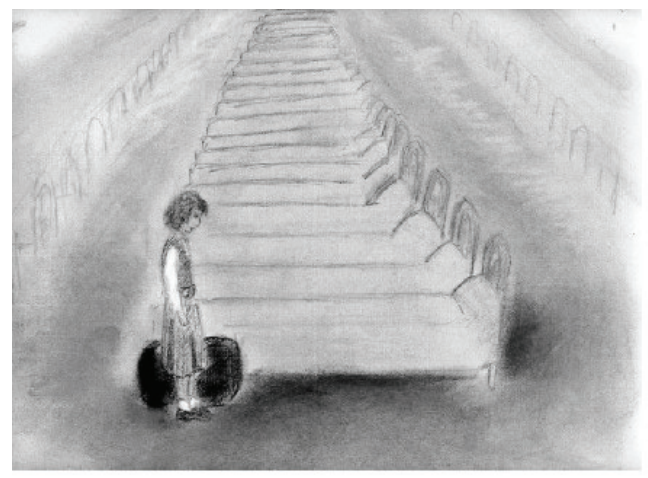

Imagen 4-1

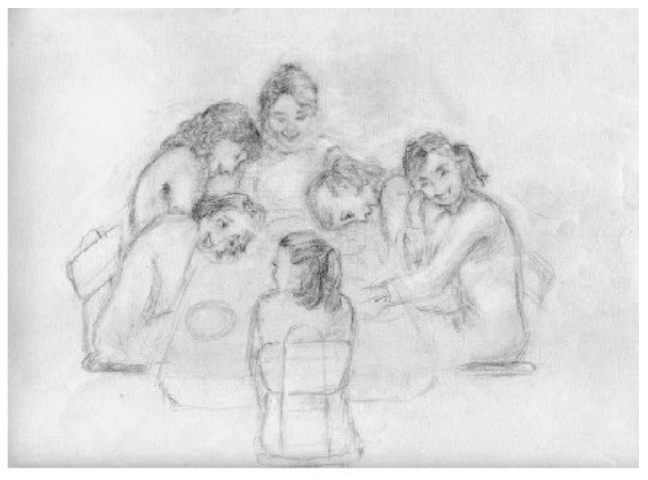

Imagen 4-2 
Lo único positivo que Elena salvó de esta época fueron las amigas con las que compartió esa experiencia, de las que también había hecho dibujos (Imagen 4-2), y con alguna de las cuales mantenía incluso todavía contacto, aunque a distancia, en la actualidad. El trabajo dio lugar a repasar sus actuales relaciones amistosas, comprobando que su desconfianza le había hecho alejarse de casi todas y que había algunas que si le gustaría recuperar. También se mostró muy satisfecha de haber podido dibujar en su casa sobre cosas personales como hacía en el taller, tal y como le habíamos sugerido desde el principio, ya que hasta entonces sólo dibujaba, plantas, flores, objetos o cualquier modelo que viera a su alrededor.

En otro de sus trabajos en el que se le pidió representar una pesadilla infantil o juvenil (Imagen 5-1), Elena se dibujó a sí misma mirando por la ventana a un mago que bailaba en la calle. No sabía por qué por un lado le fascinaba tanto y no podía dejar de contemplarlo, pero por otro le asustaba mucho. En ese momento, al poner el trabajo en común interpretó que el mago era como su marido, algo que la deslumbraba y a la vez le daba miedo, la inhibía dejándola paralizada. Pensaba que se había casado con lo que admiraba y temía a vez y se alegró de poder entender el sueño y redefinir al mago.

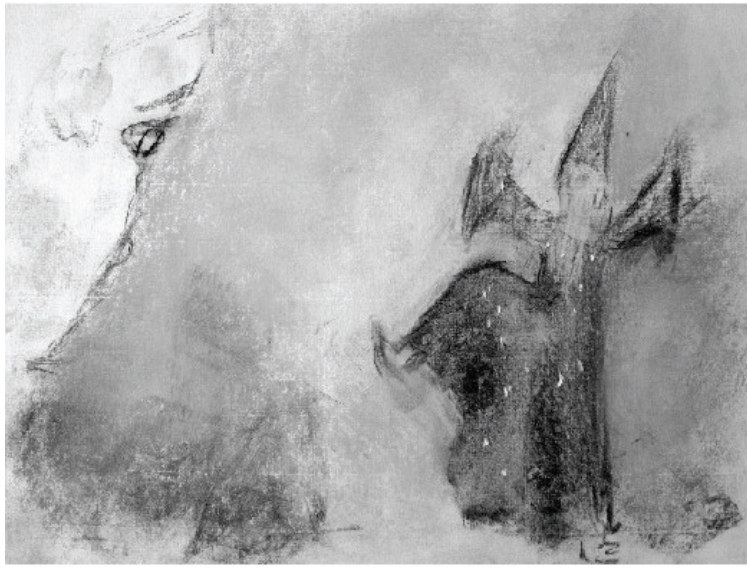

Imagen 5-1

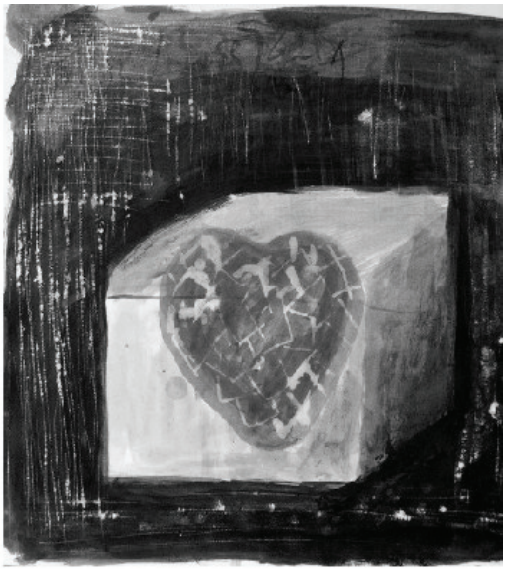

Imagen 5-2

Elaborando ese mismo sentimiento de bloqueo y miedo en otra sesión, hace una composición (Imagen 5-2) explicando que cuando esa sensación aparece, y precisamente en ese momento se sentía a menudo envuelta en ella, se veía a sí misma tal y como se representa en su trabajo, rodeada de oscuridad y encerrada en un bloque de hielo con el corazón herido. Todas alabamos la fuerza y la belleza de su imagen y concluimos que poco a poco se irían curando las heridas, se iría deshaciendo el hielo y volvería a ver la luz.

Sus primeros años de juventud, las primeras parejas y los primeros años de enamoramiento y convivencia con el maltratador fueron también trabajados en varias propuestas. Las dos más significativas se resolvieron una con collage y otra con modelado en barro. En la primera (Imagen 6-1) recordaba, después de una educa- 
ción tan restrictiva, sus primeros años de juventud como unos años felices de amistad, placer y amor, viajes, tertulias, vacaciones,... todo estaba por hacer. Sólo dos imágenes llamaban la atención en su composición, el pingüino, que identificó consigo misma, ya que en el fondo siempre se sentía un poco fuera de lugar, y el fantasma, su maltratador, ya que, aunque no empezaron a salir hasta años después y en esa época sólo eran conocidos y amigos, siempre estuvo presente de alguna forma. Él tenía una inteligencia y personalidad brillantes y era muy guapo, siempre fue un manejador y solía conseguir lo que quería.

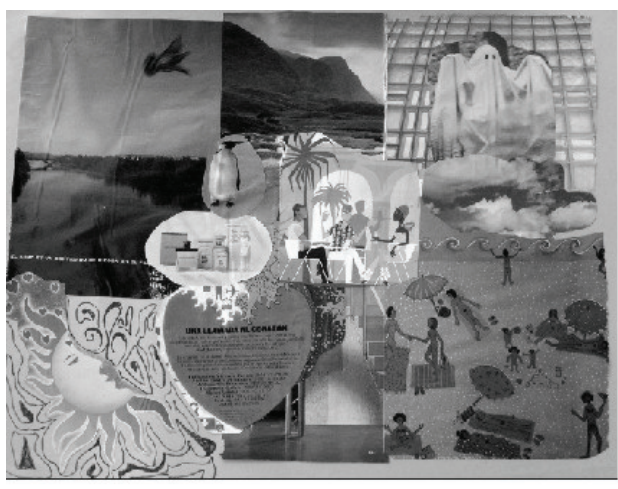

Imagen 6-1

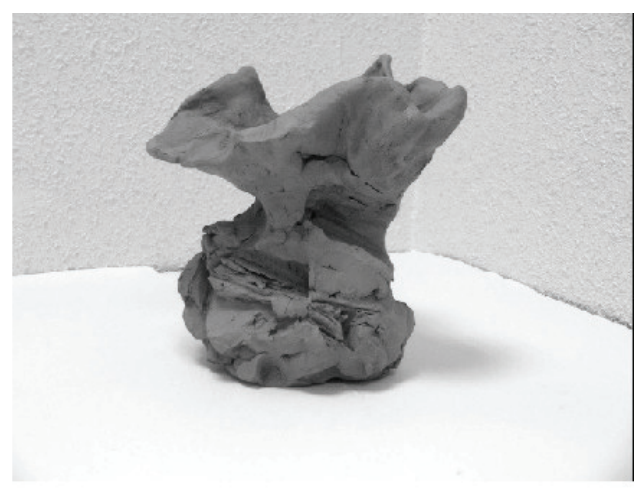

Imagen 6-2

En la segunda (Imagen 6-2), se modela a sí misma como un cáliz de flor, viviendo los primeros años de enamoramiento y convivencia con él, abierta a todas las experiencias y a vivir el amor y la delicadeza de unos afectos intensos, según sus propias palabras. Entonces nada le hacía pensar que estaba estableciendo una relación inadecuada.

En otra sesión se trabajó expresamente la figura del maltratador, se le pidió que realizara un retrato de él, después tenía que manipularlo y convertir su composición en algo positivo. Le costó bastante hacer el dibujo (Imagen 7-1), estaba tensa y de mal humor, comentó que le había salido muy feo, tan feo como era él por dentro. No había sido sino al cabo de esos meses de reflexión en el taller cuando se había dado cuenta de que desde el principio él la modeló como quiso, consiguiéndolo de una forma bastante perversa, utilizando los puntos más débiles y frágiles de su personalidad, y doblegando su voluntad a su antojo. Aún cuando ella se rebelara en ocasiones, siempre reconducía su enfado o indignación con zalamerías y manipulaciones. Incluso reconoció que en sus relaciones sexuales también era dominante y posesivo, no atendiendo siempre a sus peticiones incluso cuando le rogaba que no hiciera ciertas cosas, con lo cual de alguna manera se vio obligada a admitir que tal vez el maltrato no fue sólo psicológico. Además ante ojos de los demás era un ser encantador y triunfador, tan sólo a su padre no le gustó desde el primer momento, ni él, ni las cosas que después fue viendo en el matrimonio y, aunque se lo dijo, ella no le dio crédito. Ahora veía como fue poco a poco encerrándose en el mundo que él 
fue creando para ella y sus hijos, manteniéndolos apartados de esa otra vida que descubriría más tarde.

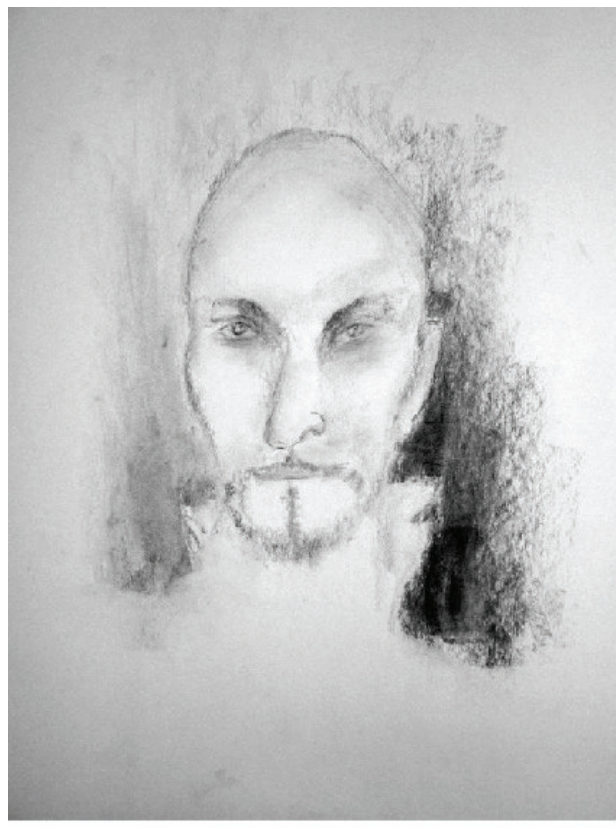

Imagen 7-1

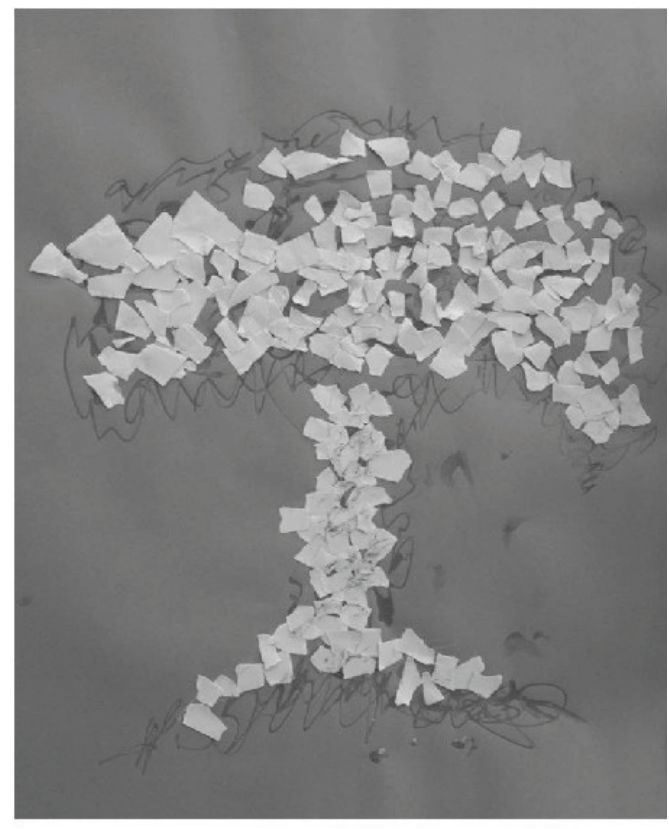

Imagen 7-2

Cuando llego el momento de manipular el retrato que había dibujado, no sabía cómo hacerlo, ni se le ocurría qué podía salir positivo de él. Al final, después de pensarlo un buen rato, rompió el papel en trocitos que fue haciendo cada vez más pequeños, sintiendo que esto le ayudaba a librarse de su imagen. Después los pegó en una cartulina construyendo un árbol, algo vivo, algo bueno, algo que no hace daño sino que procura belleza y placer (Imagen 7-2).

Antes de la segunda interrupción del taller por las vacaciones de Navidad, se hizo una revisión de todos los trabajos biográficos realizados, valorando especialmente en el caso de Elena el haber logrado desbloquear recuerdos reprimidos y la valentía de enfrentarse y analizar vivencias dolorosas. En enero se les explicó que nos íbamos a centrar en el presente y en el futuro y se les invitó también a proponer temas de reflexión que les interesasen.

Uno de los temas elegidos fue analizar la forma en que manejaban las situaciones y sus estrategias de afrontamiento de conflictos, intentando que aprendieran a distinguir aquellas en las que se ponían en una posición de vulnerabilidad, evitación o bloqueo. Se propuso trabajar con la metáfora del laberinto y se hizo una sesión previa en la que se reflexionó a partir del mito del laberinto, para ir identificando las claves y elementos que querían introducir en su representación. Se trabajó en 
volumen con materiales reciclados muchos de los cuales aportaron ellas mismas. Sobre un tablero de madera, empezaron a jugar con los elementos, moviéndolos, eliminándolos o buscando nuevas soluciones.

Elena hizo un laberinto (Imagen 8-1) sin entradas ni salidas, todo confluía en un vaso central que era ella y al que iban a parar por un lado los símbolos de las cosas importantes de su vida, el trabajo, la enfermedad y la muerte, su intimidad, sus sueños, sus retos,...y por otro, sin apenas conexiones, estaban los demás, los otros, que modela con plastilina de color verde. Desde alguno de estos últimos partía una línea larga y serpenteante que llegaba hasta ella, aunque estaba interrumpida por una figura roja que representaba a los que le habían hecho daño, al resto no les quedaba más remedio que atravesar un gran puente con una pendiente de subida y bajada muy acusada.

Cuando ya lo tenía acabado pero todavía no lo habíamos puesto en común, la metáfora del conflicto se hizo realidad en el taller y surgió un enfrentamiento entre Elena y otra de las participantes. Ella acusaba a su compañera de acaparar el protagonismo y la otra, frente al ataque, se declaró inocente pero manifestó que no sabía si podría permanecer en el grupo después de esto. Las dos aseguraron que se sentían fatal y que esta situación les producía mucha angustia y desazón. En la siguiente sesión, se consiguió analizar y solventar el problema releyendo el trabajo de sus laberintos desde la perspectiva del conflicto actual; en el origen, desarrollo y reiteración de sus conductas. Elena había reflejado en su obra el miedo y la desconfianza que le producía el acercamiento al otro y como los evitaba haciéndoles sentir su indiferencia, falta de interés o rechazo. Aseguró que esta experiencia le había reportado mucha zozobra, pero que había comprendido que estas actitudes eran los mecanismos de defensa que utilizaba ante cosas que no podía o no sabía cambiar en las relaciones. Al final pude entender algo que siempre me había preocupado: la distancia que ponía en las relaciones con los demás. Me ayudó a comprenderlo y a relacionarme con más tranquilidad.

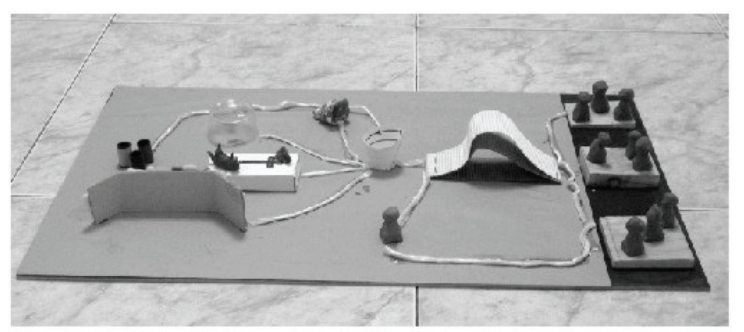

Imagen 8-1

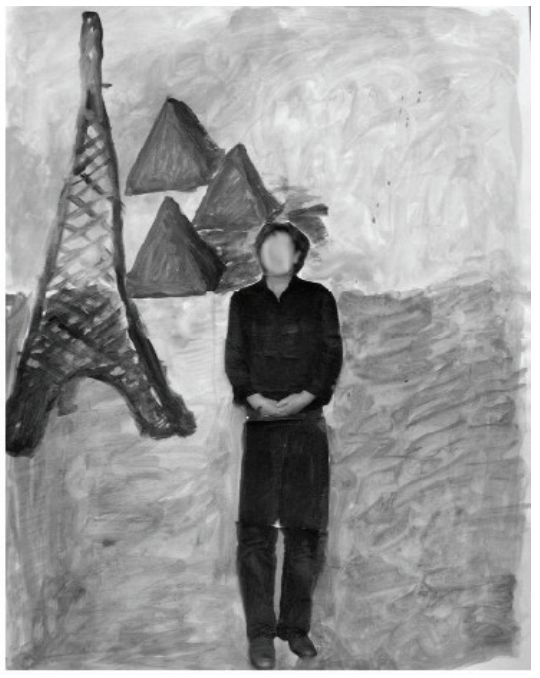

Imagen 8-2 
Otro de los temas que siempre se planteaba en los talleres, y que ellas mismas demandaban trabajar cuando se les preguntaba en qué conflictos querían profundizar, era el cómo se veían a si mismas, su propia imagen, su cuerpo. A la mujer maltratada se le usurpa el poder sobre su cuerpo y al hacerlo se le usurpa el poder sobre su vida. Agredir el cuerpo de la mujer, ya sea física, sexual o psicológicamente ese ir cerrando poco a poco esa puerta que nos conecta con el exterior, ese umbral entre el yo y el otro, que en los casos más graves será destruido, aniquilado definitivamente.

Para abordar esta cuestión y reflexionar sobre ella, en una sesión anterior se les facilitaron cámaras de foto y se les pidió que se fotografiasen unas a otras buscando ángulos y poses que a cada cual le interesaran, les gustó mucho la propuesta y se lo pasaron muy bien. En la sesión siguiente trajimos las fotografías en papel y les pedimos que las manipularan como quisieran, haciendo en una cartulina grande una representación de sí mismas utilizando libremente los materiales. Elena en su trabajo (Imagen 8-2) reprodujo su imagen pegando varias de las fotos recortadas, la rodeó con diferentes planos de colores pintados con tempera que estilizaban su figura y dibujó también la torre Eiffel y unas pirámides. En su composición su propia apariencia era tranquila, posaba mirando de frente, con las manos entrelazadas apoyadas en su regazo. Explicó que quería cuidarse más, sentirse mejor con su cuerpo, desde su separación había caído en un estado de descuido y abandono físico y sentía que necesitaba recuperar el control sobre su propia imagen. Además, siempre le había gustado mucho viajar y anhelaba mucho poder volver a hacerlo.

Uno de los últimos trabajos que se hicieron fue decorar una caja y poner en su interior todas aquellas cosas que quisieran conservar de su pasado y su presente, y aquellas que deseaban para el futuro. El trabajo de Elena fue sencillo y explícito. Decoró una caja de zapatos de forma sobria y elegante, como si fuera una caja de regalos (Imagen 9-1), dentro metió un libro, unos pinceles, el pasaporte, recuerdos, cartas, fotos,...(Imagen 9-2); para ella, según expresó era importante recuperar viejas cosas y comprobar lo que planeo para el futuro.

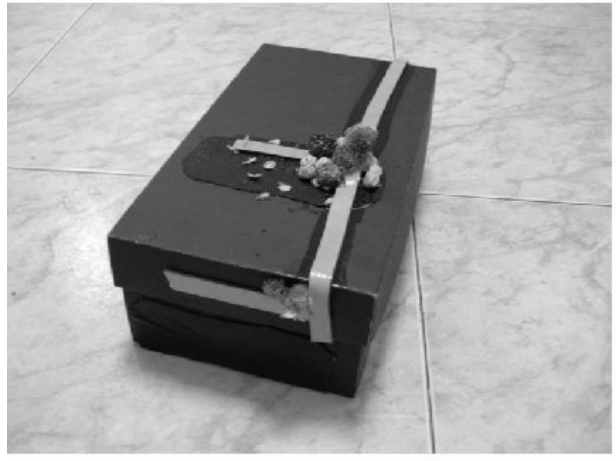

Imagen 9-1

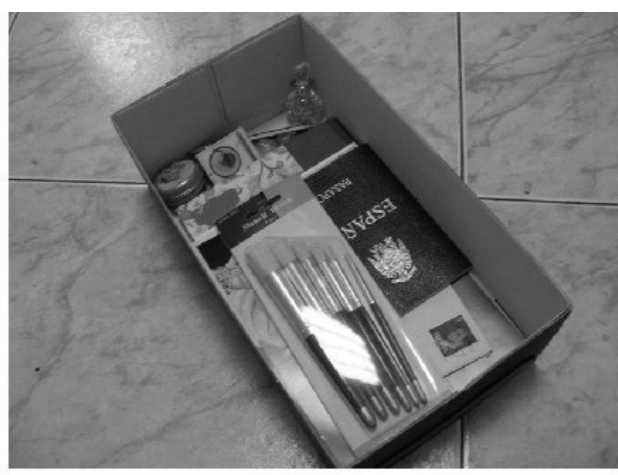

Imagen 9-2 


\section{CONCLUSIONES}

La única frase que quiero defender sin restricción alguna es que los seres humanos no pueden vivir sin esperanza

Hans-Georg Gadamer

Elena asistió prácticamente a todas las sesiones y desde el principio trabajó y se implicó mucho en las propuestas, realizando un gran trabajo de introspección, reflexión y afrontamiento. Al final del taller se hizo una revisión de todos los trabajos para que pudiera volverlos a contemplar y tener una perspectiva global de todo su esfuerzo. En la misma se le facilitó un impreso para que hiciese una reflexión y evaluación final del taller, sin darle pautas o hacerle preguntas al respecto. Ella escribió:

\section{Reflexión final}

Ha sido muy importante para mi:

1- He podido identificar y elaborar fantasmas de mi infancia.

2- He podido identificar y elaborar miedos en mis relaciones.

3- He podido identificar y elaborar qué cosas elegí.

4- Cómo me posicionaba ante lo que elegía.

Y también:
- He recuperado el corazón.
- He vuelto a tener alas.
- He tendido puentes hacia los demás.
- He establecido conexiones.

\section{Evaluación del taller}

- Me ha encantado. No era capaz de crear, tampoco de salir del conflicto y ahora lo veo posible.

- Lo que menos me ha gustado: no lo sé.

- Lo que más me ha gustado: poder expresar y reflexionar.

- Quizás con más participantes para recoger más vivencias, pero también me ha ayudado poder reconcentrarnos.

Elena nos contó que empezaba a plantearse la posibilidad de volver a su ciudad de origen, allí tenía a su familia y a viejos amigos, contactos afectivos que podían ayudarla y apoyarla, incluso pensaba que encontrar trabajo sería también más fácil. Lo había hablado con sus hijos y parecían estar de acuerdo. Meses más tarde, en los contactos esporádicos que mantuvimos, nos confirmó que había llevado a cabo sus planes y que, aunque sabía que le quedaba mucho por recorrer, creía que por fin había llegado a la luz del final del túnel, se atrevía a tener un atisbo de esperanza. 


\section{REFERENCIAS BIBLIOGRÁFICAS}

ALONSO GARRIDO, María Ángeles (2012): Mujeres y Arteterapia. Tesis doctoral, directoras Noemí Martinez y Marián López Fernández Cao. Departamento de Didáctica de la Expresión Plástica. Universidad Complutense de Madrid.

HERMAN, Judith (2004): Trauma y recuperación: cómo superar las consecuencias de la violencia. Madrid, Ed. Espasa Calpe.

LORENTE ACOSTA, Miguel (2001): Mi marido me pega lo normal. Barcelona, Editorial Ares y Mares.

MARTINEZ, Noemí y LÓPEZ FERNÁNDEZ CAO, Marián (eds.) (2009): Reinventar la vida. El arte como terapia. Madrid, Editorial Eneida.

OJEDA, Marina y SERRANO Ana (2008): "Una visión sobre la violencia de género". En Revista Arteterapia - Papeles de arteterapia y educación artística para la inclusión social, Vol.03:157-164. Universidad Complutense de Madrid. Servicio de Publicaciones.

OMENAT, M. (2006) Arteterapia con mujeres que han sufrido violencia de género: Valor y uso del objeto artístico. En Arteterapia. Dinámicas entre creación y procesos terapéuticos. Coll, F.J. (Coord.), páginas 225-263. Murcia, Servicio de Publicaciones Universidad de Murcia.

PEREIRA RODRÍGUEZ, Teresa (2009): “Acompañando a las mujeres rotas”. En Reinventar la vida. El arte como terapia, Martinez, N. y Lopez Fernandez Cao, M., 75-97. Madrid, Editorial Eneida..

PINKOLA ESTÉS, Clarissa (2001): Mujeres que corren con los lobos. Madrid, Ediciones B,

ROMITO, Patrizia (2007): Un silencio ensordecedor. La violencia ocultada contra mujeres y niños. Madrid, Montesinos.

WALKER, Leonore (1979): The Battered Woman. Harper \& Row. Nueva York 